\title{
The Computerisation of Israel's Psychiatric Case Register: Blessings and Dangers of Automated Information Systems*
}

Michael RAHAv, Director, Department of Information and Evaluation, Mental Health Services. Ministry of Health, Jerusalem, Israel; currently Visiting Research Scientist, Nathan Kline Institute for Psychiatric Research, Orangeburg, New York 10962, USA

Psychiatric case registers (PCRs) have been in operation since the beginning of this century. ${ }^{1}$ At the present time there are numerous PCRs operating in many countries around the world on a national or regional basis (e.g. Scandinavia, Ireland, Scotland, England, Spain, Italy, Yugoslavia, Israel, Japan, The Netherlands, USA).

The establishment and operation of PCRs is known to be highly costly. PCRs require a relatively large staff with a wide variety of skills and expensive hardware. It is the costliness of operating PCRs that led the WHO Expert Committee on Health Statistics to recommend caution in establishing new ones and use them only to perform tasks for which no simpler tools can be found. Others warned of establishing registers for the sheer sake of collecting statistical information, with the hope that some useful conclusions would emerge.

Against the consideration of cost stands the many benefits and advantages PCRs yield. PCRs are said to be invaluable research tools of psychiatric morbidity, by allowing the long-term observation of large patient groups, and providing the data needed to further knowledge in preventing, treating, and controlling mental diseases. In addition, PCRs generate information which may be used for rational health planning. ${ }^{1}$

A close look into the history of some of the best known PCRs around the world reveals that research and planning needs were responsible for their development and establishment. The Camberwell Register, for example, was set up as a research tool for the social psychiatry research unit. ${ }^{2}$ It was established in order to provide a sampling frame for epidemiological studies, and statistical data for evaluation and planning.

Most psychiatric case registers in operation around the world today are on the level of a county, health district, or other regional basis. The only exceptions are the national PCRs of Denmark and Israel.

The aim of this paper is to focus on Israel's National PCR. Specifically, we aim at (a) identifying the historical processes and forces that led to establishment of that PCR and its recent computerisation, and (b) evaluating the consequences of having a nationwide computerised PCR.

* An earlier version of this paper was presented at the Annual Conference on Computers and Society, University of Rochester, New York, in June 1985. (a) Identifying some of the forces that pushed towards computerisation

Since its establishment as a state in 1948, Israel has been conscientiously collecting information on all individuals admitted to in-patient psychiatric facilities. Principal identifying information for these people (names, I.D. numbers, father's name and address); demographic information (age, sex, country of origin, marital status, education, religion); and clinical information (dates of admission and discharge, diagnoses, suicide attempts, drug addiction problems, etc.) have been maintained since 1948 on alphabetically arranged cards.

Since in-patient treatment was (and still is) the main form of psychiatric treatment in Israel, and since all in-patient psychiatric facilities are required by law to report every admission and discharge, these data actually constituted a nationwide psychiatric case register (PCR). Yet, because this PCR was manual, its uses were limited not by the amount or the quality of the information it contained, but by the lack of automated data retrieval and analysis mechanisms which could make the information useful on any massive scale. The manual PCR was, therefore, mainly a one-way avenue of information. A great deal of data were input, but the register yielded almost no output.

In the mid-70s attempts to computerise the manual card register were begun. These attempts were successfully completed in 1983. Since then Israel has operated a nationwide computerised information system covering all in-patient admissions into psychiatric facilities.

The question of why and how a computerised information system comes into being is rarely a trivial one. By allocating the resources needed to establish a computerised psychiatric information system and insisting on its creation despite years of repeated failure and frustration, society reveals the importance and priority it attributes to information on the mentally ill.

Medicine generates data on all kinds of patients. There are many more cases of cardiac arrest, coronary illness, kidney, eye problems, etc. than cases of psychiatric hospitalisations. Excluding cancer, Israel has not attempted to automate any of these data files. Why then the interest in mental patients? Why has there been so much public pressure to automate psychiatric data? Why have policy makers and budget officers in both the Ministry of the Treasury and the Ministry of Health been ready and willing 
to invest almost any amount of funding in order to attain an operational computerised psychiatric information system? Do epidemiological and research interests make mental illness more important and intriguing than other areas of medicine? Is it because of an urgent need to have exhaustive, easily accessible and analysable psychiatric data for better treatment, follow-up, evaluation, budgeting and planning in the field of mental health? Are these needs more urgent for mental health than they are for other fields of medicine?

The answers to these questions, one believes, are negative. The special attention paid to Israel's psychiatric data reflects public concern about the mentally ill and the public's wish to know who the mentally ill are.

A review of certain Israeli laws and legislation may give support to this belief. For example, the Law of Treating the Mentally III requires that every admission or discharge of mental patients be reported to the Ministry of Health. This law states that information regarding mental patients must remain strictly confidential. Nevertheless, it excuses from this requirement a number of public agencies which may be characterised as over-seeing areas of 'sensitive' activities; i.e., activities that may constitute some risk to the people participating in them and/or to the people around them. The lawmakers' provision of access to confidential psychiatric information is reiterated in laws that deal specifically with the 'sensitive' areas mentioned above. Thus, the Law of Firearms, the Law of Defense Service, and the Law of Transportation all state the legal obligation of the Ministry of Health to answer their queries regarding mental patients.

It was the legal obligation of the Ministry of Health to provide psychiatric information to the agencies mentioned above, together with the insistence of these agencies to obtain this information, that pushed the computerisation of psychiatric information and forced it into being, in spite of all obstacles and hardship. The agencies involved needed the psychiatric information for their screening of applicants for 'sensitive' activities. The Firearms Registrar, for example, uses this information for screening applicants for firearms permits. The army uses the information in its recruitment of new draftees, and the Ministry of Transportation uses it in its licensing of drivers for special vehicles. $^{3}$

As long as psychiatric information was stored on cards the agencies involved had only very limited access to this information. Utilising the manual information by searching for 'a match' entailed checking a person's name against the names in the psychiatric case register. Obviously, the number of names that could be searched for was minimal. The only agency that used the PCR as a regular screening procedure was the Firearm Registry. In Israel about 40,000 people apply for handgun permits yearly. A copy of their application is sent to the Ministry of Health where the applicant's name used to be checked against the names on cards in the PCR. A result of this check, in terms of 'yes' (applicant has a record of psychiatric hospitalisation) or 'no' (applicant does not have such a record) was sent to the Firearms Registry. This procedure was long and tedious and not without error. Waiting time for an application to be processed was three to six months. But most of all, this procedure was inadequate as a means of controlling the mental health of gun holders. People who had already obtained a gun permit could develop psychiatric disorders and go undetected. For policy-makers who believe that mental and former mental patients are violent and dangerous, such a prospect was rather frightening. It was this apprehension and concern that caused the automation of psychiatric data. It is important to identify these forces of apprehension and concern when trying to understand why data banks on patients with other illnesses have never been automated (in Israel), not have other data, such as register of all physicians in Israel who are licensed to practise medicine or a list of all drugs and other pharmaceutical substances licensed by the Ministry of Health, been automated. The fear and mistrust of the mentally ill existing in Israel has been shown in a number of publications. ${ }^{4.5}$ It is reasonable to suggest that this fear and mistrust have played more important roles in bringing about the automation of psychiatric data than did interests in the epidemiology of mental disorder, the need for better data for budgeting and resource allocation, and the need for data for follow-up of patients.

(b) Consequences of computerising the psychiatric data

At the present time there is an online computer system which utilises a mainframe computer owned by a private company. Three terminals and a printer located at the Mental Health Services (Ministry of Health) are hooked up to this mainframe. All inputting and outputting of data are done by Mental Health Services personnel and only by them. The input is based on monthly reports of admissions and discharges sent from all inpatient psychiatric facilities.

The main and immediate impact of the move to a computerised system was the swift reduction in manpower. Instead of three full-time employees needed to process manually the applications for handguns, there is now one employee holding this position. Waiting time for handgun application processing was reduced to two weeks. Instead of three people once needed for recording all psychiatric information on cards, one person now performs this data entry. This reduction in manpower constitutes a major incentive for the administrators.

My main concern in this paper is, however, with the bearing of the new-born information system on brand new 'urgent' needs for information. It seems that the existence of a computerised system begets needs that had not existed prior to its inception; a few examples:

(i) After satisfying the need to screen applicants for firearms and periodically to check those who already bear firearms for possible records of recent psychiatric illness, the Ministry of Health was asked to review the psychiatric history of tens of thousands of government employees who, in light of their job responsibilities (e.g. government employees in Arab territories, security guards in government offices, bus drivers, etc.) were provided with handguns without going through the regular screening procedure. As long as there was no easy access to pychiatric records to facilitate the 
screening of those tens of thousands of individuals, this need for information did not exist. Once psychiatric information was available, the firearm authorities presented this need as having the highest priority and urgency.

(ii) As soon as the automated psychiatric information system started operating, the Israeli Defence Forces (IDF) demanded access to this information for its recruitment screening procedure. This procedure is based on the matching of two files-the psychiatric file and the cohort of new recruitees file. Israel's person number system ${ }^{6}$ makes this procedure a straightforward one. For over 30 years the IDF managed to screen its new soldiers by elaborate, sophisticated testing instruments and procedures. Yet, with the advent of the availability of automated psychiatric information, the IDF has had an 'urgent need' for this kind of information.

(iii) Not long after the initiation of the computerised information system, we received a request for information from a police unit which was investigating a murder case. The request included the names of over 300 suspects in this case. One of the detectives on the team theorised that the murderer might have been a mental patient. The police asked for a check of the $\mathbf{3 0 0}$ names for possible psychiatric records. The police investigators indicated that in the future they would be interested in receiving information such as the names of all patients who fit a profile they might draw. For example, all men, ages 20 to 30, who were admitted in the last five years and were diagnosed as schizophrenics.

(iv) Recently, an amendment to the Law of Transportation which would entail the taking away of driver licences from all drivers with a history of mental illness was proposed. Such action requires automated data to make it practical. This proposal is currently being studied by a special committee.

(c) Discussion: Confidentiality and the right for privacy vs. society's own protection and welfare

For many policy makers and public officials the introduction of a computerised psychiatric information system means an important milestone on the road to a safer, more secure society. Psychiatric information is viewed by these people as a means of controlling the mentally ill; that is, knowing who they are, where they are, and, consequently, having the ability to control and circumscribe their activities. Their constant nightmare is the image of a mental patient, armed with a gun, going amok on a shooting rampage on a busy and crowded street. This fear grows even more frightening when it is imagined that such an episode takes place in the army and may involve considerably heavier weapons. The potential for danger inherent (according to their beliefs) in mental or former mental patients carrying guns, serving in the army or driving buses is so severe that it should be prevented at all costs.

Is the assumption about the potential threat and danger emanating from the mentally ill a valid one? Are the mentally ill indeed more violent and dangerous than the rest of mankind? Evidence needed to answer these questions is sparse and inconsistent. In reviewing the literature regard- ing these questions, Rabkin ${ }^{7}$ says that fear of the mentally ill is widely held by community members, stemming from their belief that the mentally ill are violent, assaultive and socially disruptive. Mental health professionals, on the other hand, see this fear as being groundless and claim that the mentally ill are actually less likely to commit crimes and have fewer encounters with the law than the rest of the population. A review of the psychiatric literature suggests that mental patients commit fewer crimes than the general population. Rabkin shows that the critical variable is the arrest of the individual prior to hospitalisation. Patients with a prior arrest record were found to have a higher arrest record after discharge than the general population. Patients with no such prior record were found to have equal or lower arrest rates after discharge than the general population.

In the case of Israel, no studies have ever been conducted regarding the dangerousness of the mentally ill, nor have any studies ever been conducted regarding their capability to assume jobs such as drivers, guards or soldiers. The practice of excluding them from these tasks is based on beliefs and theoretical assumptions, not on facts.

A study in Israel attempted to evaluate the practice of screening gun applicants for psychiatric history. ${ }^{5}$ Based on clinical psychiatric data, clinical profiles of gun applicants in 1982 who were found to have a history of treated mental illness were drawn. The findings showed that many of those who had such a history, and consequently were denied a permit to carry guns, would have probably been found to be mentally capable to bear firearms had they been examined by a psychiatrist. These former patients had had one short hospitalisation many years ago and had not undergone any subsequent psychiatric treatment.

On the other hand, there was a group of gun applicants whose treatment history suggested serious, chronic mental illness. Some applied for guns while still in hospital. The denial of guns for this group may have indeed prevented possible mishaps and tragedies. Yet guns were denied to people whose only fault was to have a record of psychiatric hospitalisation in the very distant past.

In using psychiatric data to screen mental patients and to exclude them from certain domains of life, society faces a dilemma in having to choose between the wellbeing of the private, individual member and that of the community as a whole. The use of the data invades the privacy of the patient. It makes available to the public data that were collected under an oath of secrecy and confidentiality. These are data that were elicited from patients who believed they were protected from any indiscrete use of the intimate and personal information they shared with their doctor. For many of these patients the data are used in a punitive manner, where persons are penalised for having a record of treatment in the past, without any consideration and interest in their present state of (mental) health.

On the other side of this dilemma there is 'society,' which represents the collective wellbeing of all members of a community. From society's point of view, the damage that may be inflicted by one mental patient who, undergoing a severe psychotic episode, has access to a firearm, is con- 
siderably worse than the damages done to a person's right to privacy and confidentiality. As one Army official put it-'I prefer the exclusion of 100 young men from service in the army, even though 99 of them may be perfectly mentally fit for army service, than recruiting them and having one who, after being given a gun, commits suicide due to the stress of the training'.

Where does the computer enter this dilemma? The computer did not create this dilemma, but it certainly exacerbates it to its present painful state. Without the access to data, people's privacy and confidentiality are protected by default. The computer makes information readily available and accessible and this invites its uses. Such uses may sometimes be based on beliefs, prejudices, and personal attitudes, rather than rational, wellfounded facts. The computerisation of the psychiatric data of Israel is a case in point. It introduced new opportunities for research and better tools for budgeting and planning. The computer allows for careful and differential restriction of mental patients from certain tasks and activities. But it also introduced new means by which society might exercise its prejudice and rejection of the mentally ill, label them and exclude them. If these dangers of the computer are not recognised, and if psychiatric data continue to be used to exclude the mentally ill indiscriminately, society will cut the very branch on which psychiatry stands: confidentiality. If psychiatry and hospitals cannot offer their patients the protection and confidentiality of their personal, private and intimate secrets, patients will be discouraged from seeking and pursuing help and treatment. If such pursuit of treatment implies social sanctions and penalties, why look for it? Computers, like any other sorcerer's apprentices, can turn on those who created them if society becomes too enthusiastic about their wonders and looks with limited vision upon their potential liabilities.

One last word of summary and clarification. This paper has shown possible risk and damage done to the field of psychiatry and mental patients resulting from the computerisation of psychiatric information. This is in no way to suggest reversing psychiatric information back to manual or destroying and eliminating all automated psychiatric data. Quite the contrary! The computer is always objective and benign. It is the users of the computer, their attitudes and beliefs that can make the uses of automated data beneficial and benevolent, or ill and hurting. In the case of Israel, the computerised psychiatric information has opened new avenues of inquiry and research. A few studies already done by the use of computer yielded intriguing and promising findings (e.g. Goodman, et al, 1984). ${ }^{8}$

The potential of the computer in allowing medical care to be improved through better followup, planning and budgeting, is beginning to be recognised. The paper also showed, that under certain circumstances, for certain mental patients, the invasion of privacy and confidentiality might be justified in light of the severity of the illness and the potential danger to the patient and others.

On the other hand, the example of Israel's PCR has demonstrated how computerised psychiatric information systems can turn into a major means of social labelling and control of the mentally ill. This computerisation is occurring in an era of deinstitutionalisation of mental patients and their return back to the community. Opening the gates of confidential psychiatric information to the public for screening people for possible psychiatric records may destroy years of rehabilitative therapy and treatment of former mental patients now residing in the community. It turns these former mental patients into an outcast group whose movements about the community and the tasks its members may assume are liable to psychiatric screenings. The more aware and sensitive we become to the trade-off between the protective privilege of mental patients and public peril, the more ready we are for an era of automated, computerised data.

\section{REFERENCES}

'World Health Organization (1985) The Use of Psychiatric Case Registers in Public Health. Report of a WHO working group. WHO Collaborating centre, Groningen, The Netherlands.

${ }^{2}$ Wing, L., Wing, J. K., Halley, A. \& TAYLoR, C. (1970) Camberwell Psychiatric Case Register 1964-1968: Tables and brief annotations. Psychiatric Case Registers, DHSS Statistical Report Series, No. 8, London: Her Majesty's Stationery Office.

${ }^{3}$ RAHAV, M. (1985) Labelling the mentally ill through psychiatric records: The Israeli case. Israel Journal of Psychiatry and Related Sciences, 22(3): 221-231.

'Zohar, M., FLoro, S. \& Modan, B. (1974) The image of mental illness and the mentally ill in the Israeli society. Harefuah, 391-399 (Hebrew).

${ }^{5}$ RAhAv, M., Struening, E. L. \& ANDREWs, H. (1984) Opinions on mental illness in Israel. Social Science and Medicine, 19(11), 1151-1158.

'US Departaent of Health \& Human Services (1980) The Person Number System of Sweden, Norway, Denmark and Israel. DHSS Publication No. (PHS) 80-1358, Series 2, No. 84, Hyattsville, Md.

'RABKIN, J. G. (1979) Criminal behaviour of discharged mental patients: A critical appraisal of the research. Psychological Bulletin, 86(1), 1-27.

8Goodman, A. B., Rahav, M., Popper, M., Ginath, Y. \& Pearl, E. (1984) The reliability of psychiatric diagnosis in Israel's Psychiatric Case Register. Acta Psychiatrica Scandinavica, 69, 391-397.

A full list of references is available from the author on request. 